\title{
Parasympathetic dysfunction is associated with insulin resistance in fructose-fed female rats
}

\author{
J.O. Brito ${ }^{1}$, K. Ponciano1, D. Figueroa1 , N. Bernardes ${ }^{1}$, İ.C. Sanches ${ }^{1}$, M.C. Irigoyen ${ }^{2}$ \\ and K. De Angelis ${ }^{1}$ \\ ${ }^{1}$ Laboratório de Movimento Humano, Universidade São Judas Tadeu, São Paulo, SP, Brasil \\ 2Unidade de Hipertensão, Instituto do Coração, Faculdade de Medicina, Universidade de São Paulo, \\ São Paulo, SP, Brasil
}

Correspondence to: K. De Angelis, Rua Taquari, 546, 03166-000 São Paulo, SP, Brasil

Fax: +55-11-3085-7887. E-mail: prof.kangelis@usjt.br

\begin{abstract}
The objective of the present study was to identify metabolic, cardiovascular and autonomic changes induced by fructose overload administered in the drinking water of rats for 8 weeks. Female Wistar rats $(200-220 \mathrm{~g})$ were divided into 2 groups: control $(\mathrm{N}=8)$ and fructose-fed rats $(\mathrm{N}=5 ; 100 \mathrm{mg} / \mathrm{L}$ fructose in drinking water for 8 weeks). The autonomic control of heart rate was evaluated by pharmacological blockade using atropine $(3 \mathrm{mg} / \mathrm{kg})$ and propranolol $(4 \mathrm{mg} / \mathrm{kg})$. The animals were submitted to an intravenous insulin tolerance test (ITT) and to blood glucose measurement. The fructose overload induced a significant increase in body weight $(\sim 10 \%)$ and in fasting glycemia ( 28\%). The rate constant of glucose disappearance (KITT) during ITT was lower in fructose-fed rats $(3.25 \pm 0.7 \% / \mathrm{min})$ compared with controls $(4.95 \pm 0.3 \% / \mathrm{min}, \mathrm{P}<0.05)$ indicating insulin resistance. The fructose-fed group presented increased arterial pressure compared to controls $(122 \pm 3 \mathrm{vs} 108 \pm 1 \mathrm{mmHg}, \mathrm{P}<0.05)$ and a reduction in vagal tonus $(31 \pm 9$ vs $55 \pm 5 \mathrm{bpm}$ in controls, $\mathrm{P}<0.05)$. No changes in sympathetic tonus were observed. A positive correlation, tested by the Pearson correlation, was demonstrable between cardiac vagal tonus and KITT $(r=0.8, P=0.02)$. These data provided new information regarding the role of parasympathetic dysfunction associated with insulin resistance in the development of early metabolic and cardiovascular alterations induced by a high fructose diet.
\end{abstract}

Key words: Female rats; Fructose; Blood pressure; Insulin resistance; Parasympathetic nervous system

Research supported by FAPESP (\#05/60829-2, \#05/60827-0, \#05/60828-6, \#07/057595-5) and CAPES-PROSUP.

Received May 23, 2007. Accepted July 17, 2008

Consumption of large quantities of fructose by humans and animals leads to insulin resistance, lipid abnormalities, obesity, hypertension and renal dysfunction (1-5). The cluster of these metabolic alterations, which are related to increased cardiovascular risk, is known as metabolic syndrome, and has reached epidemic levels in the world (1).

Several studies have shown that the large increase of fructose consumption in the last decades has paralleled the increased obesity observed in the occidental population $(1,2)$. Indeed, it has been demonstrated that the exposure of the liver to large quantities of fructose leads to the rapid stimulation of lipogenesis, which contributes to tri- glyceride accumulation. Thus, fructose feeding reduces insulin sensitivity, induces development of hepatic insulin resistance/glucose intolerance and dyslipidemia $(1,2)$.

Previous studies demonstrated that a high fructose intake in experimental animals leads not only to metabolic alterations, but also to cardiovascular, renal and autonomic dysfunction that are frequently accompanied by activation of sympathetic and renin-angiotensin systems (2-6). An association between hyperinsulinemia and hypertension in humans and animals has been demonstrated $(4,7)$. However, the role of the autonomic nervous system in metabolic and cardiovascular dysfunctions induced by high fructose diet is not well understood, mainly regarding 
the female gender $(5,6,8)$.

The objective of the present study was to investigate metabolic, cardiovascular and autonomic changes induced by fructose overload in drinking water of female rats.

Experiments were performed on female Wistar rats (70 days old; $200-220 \mathrm{~g}$ ) from the animal house of São Judas Tadeu University, São Paulo, SP. Rats received standard laboratory chow (Nuvital, Brazil) and water ad libitum. They were housed in individual cages and kept in a temperaturecontrolled room $\left(22^{\circ} \mathrm{C}\right)$ with a 12-h dark-light cycle. All rats were treated similarly in terms of daily manipulation, and all surgical procedures and protocols used were in accordance with the Ethical Care Guidelines of Experimental Animals. The protoicol was approved by the International Animal Care and Use Committee.

Two experimental groups of Wistar rats were used: control rats $(C ; N=8)$ and rats fed fructose $(F ; N=5)$. The experimental group received $D$-fructose in drinking water $(100 \mathrm{~g} / \mathrm{L})$ for 8 weeks.

Chow and water (with or without fructose) consumption were measured weekly. The total caloric intake was calculated using $2.89 \mathrm{kcal}$ per gram of chow consumed and that each ingested gram of fructose corresponds to $4.0 \mathrm{kcal}$.

After 8 weeks of fructose overload, the blood glucose of all animals was measured after a 4-h fast with a glucosimeter (ACCU-CHEK Advantage, Roche, Brazil). Rats were also submitted to an intravenous insulin tolerance test (ITT) after a 2-h fast. Animals were anesthetized with thiopental (40 mg/kg body weight, ip), and a drop of blood from the tail was collected to measure blood glucose by using a glucosimeter (ACCU-CHEK). This procedure was performed at 0 time, $4,8,12$, and 16 min after insulin administration $(0.75 \mathrm{U} / \mathrm{kg})$. The rate constant for blood glucose disappearance (KITT) was calculated using the formula $0.693 / t 1 / 2$, and the blood glucose half-time (t1/2) was calculated from the slope of the least squares regression of the blood glucose concentration during the linear phase of decline (9).

After metabolic measurements, two catheters filled with $0.06 \mathrm{~mL}$ saline were implanted into the carotid artery and jugular vein (PE-10) of anesthetized rats $(80 \mathrm{mg} / \mathrm{kg}$ ketamine $+12 \mathrm{mg} / \mathrm{kg}$ xylazin) for direct measurements of arterial pressure (AP) and drug administration, respectively. One day after catheter placement, the arterial cannula was connected to a strain-gauge transducer (Blood Pressure $\mathrm{XDCR}, \mathrm{Kent}^{\odot}$ Scientific, USA), and AP was recorded over a 30-min period by a microcomputer equipped with an analog-to-digital converter board (CODAS, 2-kHz sampling frequency, Dataq Instruments, Inc., USA). During the experiment the rats were conscious and allowed to move freely. The recorded data were analyzed on a beat-to-beat basis to quantify changes in mean $\mathrm{AP}$ and heart rate $(\mathrm{HR})$ (10).

Vagal and sympathetic tonus and intrinsic HR were determined by injecting methylatropine $(3 \mathrm{mg} / \mathrm{kg}$, iv, Sigma, USA) and propranolol (4 mg/kg, iv, Sigma) in a dose of $0.1 \mathrm{~mL} / 100 \mathrm{~g}$ body weight. Resting HR was recorded while rats were in their cages in an unrestrained state. Methylatropine was injected immediately after basal readings were taken. Because the HR response to these drugs reaches its peak within 5 to $10 \mathrm{~min}$, HR recordings were initiated after $5 \mathrm{~min}$.

Propranolol was injected 15 min after methylatropine, and the response was evaluated again after simultaneous blockade with propranolol and methylatropine. On the next day, the sequence of injections was inverted, first, propranolol and then methylatropine. Intrinsic HR was evaluated after simultaneous blockade with propranolol and methylatropine, and sympathetic tonus was determined as the difference between maximum HR after methylatropine injection and intrinsic HR. Vagal tonus was obtained by the difference between the lowest HR after propranolol injection and intrinsic HR (10). All metabolic and cardiovascular evaluations were performed in the non-ovulatory phases of estrous cycle.

Data are reported as means \pm SEM and were compared using two-way ANOVA followed by the NewmanKeuls test for multiple comparisons or by the Student unpaired $t$-test, when appropriate. The Pearson correlation procedure was used to identify an association between variables. The significance level was considered to be $\mathrm{P}<0.05$.

Body weight was not statistically different between the groups at the beginning of the protocol (C: $204 \pm 2$ vs $\mathrm{F}: 212 \pm 5 \mathrm{~g}$ ); however, the fructose-fed rats had a significant increase in body weight at the end of 8 weeks (C: 230 \pm 6 vs $\mathrm{F}: 252 \pm 9 \mathrm{~g}$ ). Chow consumption was similar for control $\left(16 \pm 1 \mathrm{~g} \cdot\right.$ day $^{-1} \cdot$ rat $\left.^{-1}\right)$ and fructose-fed rats $(14 \pm 1$ $\mathrm{g} \cdot$ day $\left.^{-1} \cdot \mathrm{rat}^{-1}\right)$. The fructose-fed animals, however, presented statistically significant greater water consumption (54 \pm 1 $\mathrm{mL} /$ day) compared to control rats (35 $\pm 2 \mathrm{~mL} / \mathrm{day})$. The total caloric intake (chow + fructose) was higher for the fructose-fed group (61 $\pm 2 \mathrm{kcal} / \mathrm{day})$ than for the control group (46 $\pm 3 \mathrm{kcal} / \mathrm{day}, \mathrm{P}<0.05)$.

Blood glucose was increased in fructose-fed rats after $4 \mathrm{~h}$ of fasting ( $83 \pm 5 \mathrm{mg} / \mathrm{dL}$ ) compared to control rats (65 $\pm 4 \mathrm{mg} / \mathrm{dL}, \mathrm{P}<0.05$ ), but there were no differences between the groups in ITT glycemia after $2 \mathrm{~h}$ of fasting. During ITT, fructose-fed animals presented higher glycemia, 8, 12, and 16 min after insulin administration, compared to the control group (Figure $1 \mathrm{~A}$ ). Consequently, the rate constant for blood glucose disappearance (KITT) was 
A
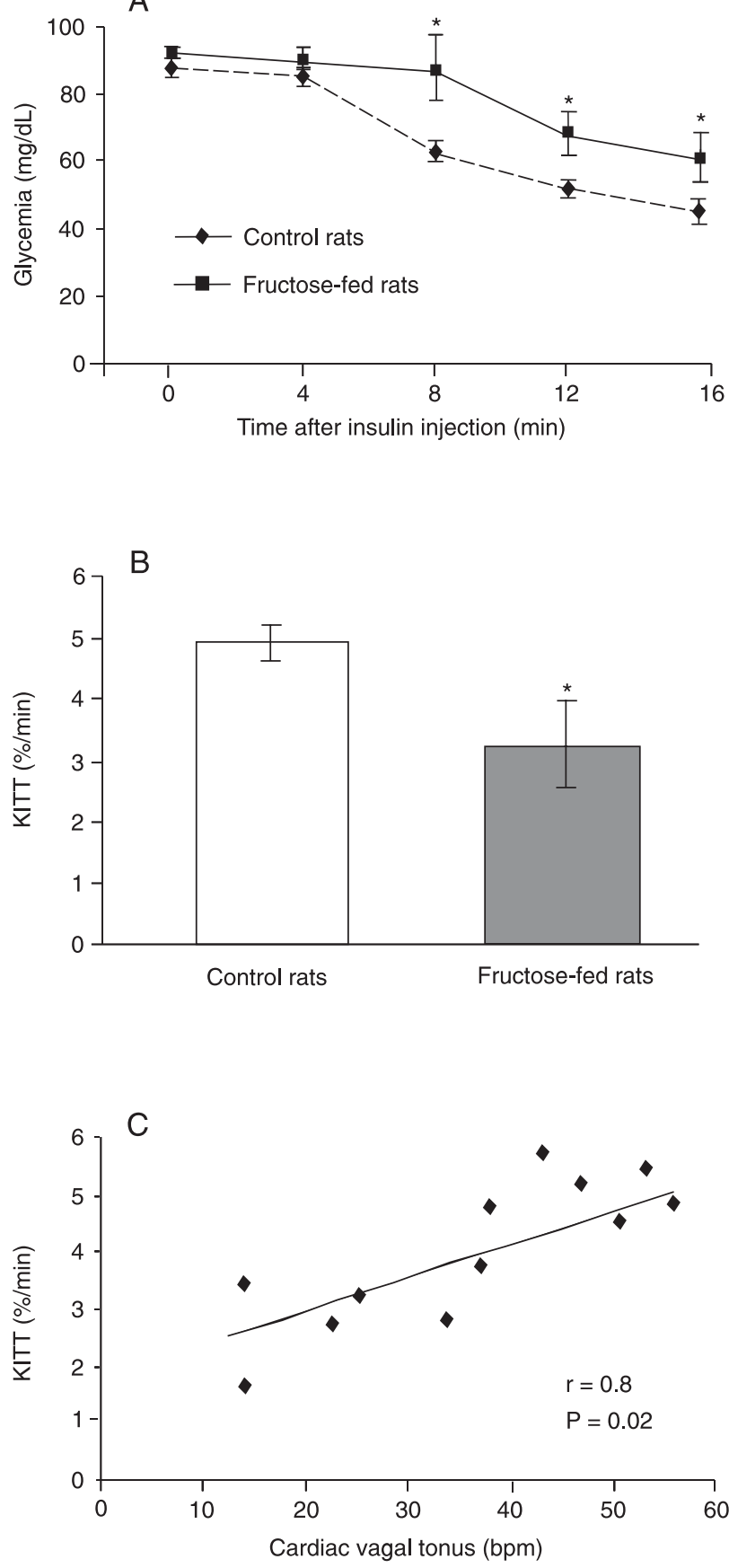

Figure 1. $A$, Blood glucose levels in fructose-fed $(N=5)$ and control $(\mathrm{N}=8)$ female rats during insulin tolerance test. ${ }^{*} \mathrm{P}<0.05$ compared to control group (two-way ANOVA followed by the Student Newmann Keuls test). $B$, Rate constant of glucose disappearance (KITT) of frutose-fed $(\mathrm{N}=5)$ and control $(\mathrm{N}=8)$ female rats. ${ }^{*} \mathrm{P}<0.05$ compared to control group (Student unpaired $t$-test). $C$, Positive Pearson correlation $(r=0.8, P=0.02)$ obtained by linear regression between cardiac vagal tonus and KITT for frutose-fed $(N=5)$ and control $(N=8)$ female rats. ${ }^{*} \mathrm{P}<$ 0.05 vs control group.
Table 1. Effect of frutose overload on cardiovascular and autonomic parameters of fructose-fed female rats.

\begin{tabular}{lcc}
\hline Parameters & $\begin{array}{c}\text { Control group } \\
(\mathrm{N}=8)\end{array}$ & $\begin{array}{r}\text { Fructose-fed } \\
\text { group }(\mathrm{N}=5)\end{array}$ \\
\hline SAP $(\mathrm{mmHg})$ & $122 \pm 2$ & $136 \pm 4^{*}$ \\
DAP (mmHg) & $93 \pm 2$ & $103 \pm 3^{*}$ \\
MAP (mmHg) & $108 \pm 1$ & $122 \pm 3^{*}$ \\
HR (bpm) & $372 \pm 10$ & $363 \pm 11$ \\
Vagal tonus (bpm) & $55 \pm 5$ & $32 \pm 9^{*}$ \\
Sympathetic tonus (bpm) & $38 \pm 9$ & $40 \pm 13$ \\
Intrinsic HR (bpm) & $368 \pm 5$ & $377 \pm 17$
\end{tabular}

Data are reported as mean \pm SEM. SAP $=$ systolic arterial pressure; $\mathrm{DAP}=$ diastolic arterial pressure; $\mathrm{MAP}=$ mean arterial pressure; $\mathrm{HR}=$ heart rate.

${ }^{*} \mathrm{P}<0.05$ vs control group (Student unpaired $t$-test).

reduced in the fructose-fed rats $(3.25 \pm 0.7 \% / \mathrm{min}) \mathrm{com}$ pared to the control group $(4.95 \pm 0.3 \% / \mathrm{min})$ (Figure 1B), providing evidence of insulin resistance in fructose-fed rats $(P<0.05)$.

The fructose-fed group presented an increase in systolic, diastolic and mean arterial pressure (Table 1). Resting HR values were similar for both groups (Table 1). A reduction in cardiac vagal tonus was observed in fructosefed rats compared to control rats $(P<0.05)$. No differences were detected in cardiac sympathetic tonus or in intrinsic HR between groups at the end of 8 weeks (Table 1).

A positive correlation was obtained between the vagal tonus and the KITT $(r=0.8, P=0.02)$, showing that animals with reduced cardiac parasympathetic tonus also presented increased insulin resistance (Figure 1C).

The results of the present study suggest that autonomic dysfunction can play a role in the development of early metabolic and cardiovascular alterations induced by a high fructose diet.

Contrary to other studies in males $(3,5,11,12)$, our data showed that fructose-fed female rats presented increased body weight gain, which can be explained by the form in which fructose was provided (water vs chow) and by gender differences $(5,11,13)$.

Previous studies reported an increase in AP in fructose-fed males by indirect systolic AP measurement by the tail-cuff method and direct AP evaluation by telemetry $(5,9)$. However, AP evaluated indirectly (tail-cuff method) did not change in female rats after fructose treatment in chow (11). In the present study, there was an AP increase in female rats submitted to a fructose overload, provided in the water, by direct AP measurements after catheterization, providing a high degree of accuracy for this parameter.

Several studies have suggested that insulin resistance, 
which was observed in the fructose-fed group of the present study, and hyperinsulinemia are the main causes for increased AP in the fructose model, and they are possibly responsible for sympathetic nervous system activation (6), impairment of endothelium-dependent relaxation $(12,14)$ and dysfunction in angiotensin-renin system (5).

This is the first study to evaluate cardiac autonomic control in female rats after high fructose consumption, using an invasive method. The female fructose-fed rats presented reduced vagal tonus, without changes in sympathetic tonus and in intrinsic HR. We previously reported that male and female ovariectomized streptozotocin-induced diabetic rats presented reduced vagal tonus and unchanged sympathetic tonus to the heart compared to control male rats $(10,15)$. Moreover, a recent study reported increased sympathetic modulation of the circulation during the dark (active) period that was demonstrated by the increase in low frequency component of systolic AP; however, no changes in autonomic modulation to the heart were observed in those male mice submitted to fructose overload (5). There are several possibilities to explain these differences in fructose-induced autonomic alterations to the heart or to the vessels: the form that fructose was provided (chow or water), the autonomic function method

1. Basciano H, Federico L, Adeli K. Fructose, insulin resistance, and metabolic dyslipidemia. Nutr Metab 2005; 2: 5.

2. Elliott SS, Keim NL, Stern JS, Teff K, Havel PJ. Fructose, weight gain, and the insulin resistance syndrome. Am J Clin Nutr 2002; 76: 911-922.

3. Cunha TS, Farah V, Paulini J, Pazzine M, Elased KM, Marcondes FK, et al. Relationship between renal and cardiovascular changes in a murine model of glucose intolerance. Regul Pept 2007; 139: 1-4.

4. Hwang IS, Ho H, Hoffman BB, Reaven GM. Fructose-induced insulin resistance and hypertension in rats. Hypertension 1987; 10: 512-516.

5. Farah V, Elased KM, Chen Y, Key MP, Cunha TS, Irigoyen $\mathrm{MC}$, et al. Nocturnal hypertension in mice consuming a high fructose diet. Auton Neurosci 2006; 130: 41-50.

6. Verma S, Bhanot S, McNeill JH. Sympathectomy prevents fructose-induced hyperinsulinemia and hypertension. Eur $J$ Pharmacol 1999; 373: R1-R4.

7. De Angelis Lobo d'Avila K, Gadonski G, Fang J, Dall'Ago P, Albuquerque VL, Peixoto LR, et al. Exercise reverses peripheral insulin resistance in trained L-NAME-hypertensive rats. Hypertension 1999; 34: 768-772.

8. Vasudevan $\mathrm{H}$, Xiang $\mathrm{H}, \mathrm{McNeill} \mathrm{JH}$. Differential regulation of insulin resistance and hypertension by sex hormones in fructose-fed male rats. Am J Physiol Heart Circ Physiol of evaluation, the species, and gender differences. Regarding gender differences, the higher vagal component, previously reported in females compared to males (16), is one possibility that can explain why the autonomic dysfunction began through the parasympathetic system in females. Furthermore, in the present study, the sympathetic tonus was unchanged and the vagal tonus was reduced, the autonomic balance (sympathetic/parasympathetic) was changed, leading to a sympathetic predominance, as previously reported for male fructose models (5).

In a model of insulin-resistance of fructose-fed male rats, Miller et al. (17) showed autonomic dysfunction by impairment of baroreflex and vagal dysfunction in the absence of confounding factors such as obesity and severe hyperglycemia or AP elevation. Confirming these data, we obtained a positive correlation between reduced cardiac vagal tonus and insulin resistance in female rats, reinforcing the relationship between autonomic and metabolic dysfunctions. Importantly, Valensi et al. (18) demonstrated that hepatic parasympathetic impairment was associated with the development of insulin resistance, which predates the overt development of type 2 diabetes.

2005; 289: H1335-H1342.

9. Bonora E, Moghetti P, Zancanaro C, Cigolini M, Querena M, Cacciatori $\mathrm{V}$, et al. Estimates of in vivo insulin action in man: comparison of insulin tolerance tests with euglycemic and hyperglycemic glucose clamp studies. J Clin Endocrinol Metab 1989; 68: 374-378.

10. De Angelis KL, Oliveira AR, Dall'Ago P, Peixoto LR, Gadonski $G$, Lacchini $S$, et al. Effects of exercise training on autonomic and myocardial dysfunction in streptozotocindiabetic rats. Braz J Med Biol Res 2000; 33: 635-641.

11. Galipeau D, Verma S, McNeill JH. Female rats are protected against fructose-induced changes in metabolism and blood pressure. Am J Physiol Heart Circ Physiol 2002; 283: $\mathrm{H} 2478-\mathrm{H} 2484$.

12. Song D, Arikawa E, Galipeau D, Battell M, McNeill JH. Androgens are necessary for the development of fructoseinduced hypertension. Hypertension 2004; 43: 667-672.

13. D'Angelo G, Elmarakby AA, Pollock DM, Stepp DW. Fructose feeding increases insulin resistance but not blood pressure in Sprague-Dawley rats. Hypertension 2005; 46: 806811.

14. Verma S, Bhanot S, Yao L, McNeill JH. Defective endothelium-dependent relaxation in fructose-hypertensive rats. $\mathrm{Am}$ J Hypertens 1996; 9: 370-376.

15. Souza SB, Flues K, Paulini J, Mostarda C, Rodrigues B, 
Souza LE, et al. Role of exercise training in cardiovascular autonomic dysfunction and mortality in diabetic ovariectomized rats. Hypertension 2007; 50: 786-791.

16. Evans JM, Ziegler MG, Patwardhan AR, Ott JB, Kim CS, Leonelli FM, et al. Gender differences in autonomic cardiovascular regulation: spectral, hormonal, and hemodynamic indexes. J Appl Physiol 2001; 91: 2611-2618.

17. Miller AW, Sims JJ, Canavan A, Hsu T, Ujhelyi MR. Im- paired vagal reflex activity in insulin-resistant rats. $J$ Cardiovasc Pharmacol 1999; 33: 698-702.

18. Valensi P, Nguyen TN, Idriss S, Cazes P, Karam G, Paries $J$, et al. Influence of parasympathetic dysfunction and hyperinsulinemia on the hemodynamic response to an isometric exercise in non-insulin-dependent diabetic patients. Metabolism 1998; 47: 934-939. 